\title{
ЗНАЧЕНИЕ МИКРОЭЛЕМЕНТОВ В ПИТАНИИ СТУДЕНТОВ
}

\author{
А.В. Берестова , О.В. Баранова, В.П. Попов, О.В. Кван \\ Оренбургский государственный университет, г. Оренбург, пр. Победы, 13 \\ *e-mail: alladin1977@mail.ru
}

РЕЗЮМЕ. Развитие и функционирование молодого здорового организма невозможно без микроэлементов. Недостаток или избыток их в рационе питания может привести к возникновению различных заболеваний, снижению работы центральной нервной системы, что может отразиться на умственной и физической деятельности студента. При исследовании студенческих рационов важно не только выявить поступление каких микроэлементов не соответствует нормам, но и должным образом скорректировать питание в отношении качественного и количественного состава атомовитов. В связи с этим более рациональным и правильным решением данной проблемы являются меры, направленные не только на лечение, но и на профилактику заболеваний. Для осуществления этих мер необходимо регулярно проводить беседы о пользе правильного питания, соблюдения режима питания, чтобы каждый молодой человек осознавал, что его здоровье во многом зависит от него самого.

КЛЮЧЕВЫЕ СЛОВА: микроэлементы, атомовиты, метаболизм.

\section{THE IMPORTANCE OF TRACE ELEMENTS IN THE NUTRITION OF STUDENTS}

\author{
A.V. Berestova*, O.V. Baranova, V.P. Popov, O.V. Kvan \\ Orenburg State University, Orenburg, Pobedy ave, 13 \\ *e-mail: alladin1977@mail.ru
}

ABSTRACT. The development and functioning of a young healthy body is impossible without trace elements. If there is a lack or excess of them in the diet, this can lead to various diseases, a decrease in the work of the central nervous system, which will undoubtedly affect the mental and physical activity of the student. When studying student diets, it is important to identify not only the intake of which trace elements does not meet the standards, but also to properly adjust the nutrition in relation to the qualitative and quantitative composition of atomovites. In this regard, a more rational and correct solution to this problem is measures aimed not only at the treatment, but also at the prevention of diseases. To implement these measures, it is necessary to regularly conduct conversations about the benefits of proper nutrition, compliance with the diet, so that every young person understands that his health largely depends on himself.

KEYWORDS: trace elements, atomovites, metabolism.

\section{ВВЕДЕНИЕ}

Микроэлементы - важный компонент сбалансированного рациона питания населения, поскольку течение многих биохимических процессов метаболизма невозможно без них. Особенно этот компонент актуален для студенчества, так как многие молодые люди начинают самостоятельную жизнь вдали от родителей, и процесс организации правильного питания обычно оставляет желать лучшего.

Очень многие обучающиеся страдают железодефицитной анемией, которая связана с недостаточным содержанием в рационе железа. При возникновении заболевания у человека наблюдается слабость, упадок сил, головокружение, снижение концентрации внимания - все это в конечном итоге приводит к снижению успеваемости, потере интереса к учебе.

\section{РЕЗУЛЬТАТЫ И ОБСУЖДЕНИЕ}

Для Оренбургской области проблема йододефицита является очень актуальной. Йод входит в состав тиреотропного гормона и тиреоидных гормонов щитовидной железы. Особенно важна нормальная функция щитовидной железы для людей с умственными нагрузками, коими являются студенты. При дефиците йода наблюдается повышенная утомляемость, вялость, ухудшение памяти и внимания, понижение интеллекта. Выборочное анкетирование студентов Оренбургского государственного университета, где молодые люди указывали свой пятидневный рацион, показало, что в питании студентов наблюдается недостаток йода, магния, цинка, а содержание натрия увеличено в 1,7 раза. 
Полученные результаты объясняются тем, что в основном рацион студентов качественно и количественно не сбалансирован, режим питания не выдержан, присутствует большой процент продуктов из фастфуда, которые содержат в своем составе много поваренной соли. Кроме того, молодые люди крайне редко включают в свой рацион такие продукты, как овощи, фрукты, рыбу, морепродукты из-за их высокой стоимости.

\section{ВЫВОДЫ}

Последствия не сбалансированного питания могут проявиться в виде различных заболеваний, не только в настоящий период, но и через несколько лет. В связи с этим более рациональным и правильным решением данной проблемы являются меры, направленные не только на лечение, но и на профилактику заболеваний (Берестова, Пустарнакова, 2013; Baranova at al., 2014). Для осуществления этих мер необходимо регулярно проводить беседы о пользе правильного питания, соблюдения режима питания, чтобы каждый молодой человек осознавал, что его здоровье во многом зависит от него самого.

\section{Список литературы / References}

1. Берестова A.В., Пустарнакова И.А. Научные основы производства функциональных продуктов питания, обогащенных йодированным белком «биойод». Университетский комплекс как региональный центр образования, науки и культуры: материалы Всерос. науч.-метод. конф. (с междунар. участием), 30 янв. - 1 февр. 2013 г., Оренбург. Оренбург: Университет. 2013: 926-929.

2. Baranova O. et al. Elemental analyses of hair of orenburg region's students [Электронный pecypc]. Life Science Journal. 2014; 11 (10): 556-558. 